\title{
ДОМАШНИЕ ПТИЦЫ В РУССКОЙ, ПОЛЬСКОЙ И АНГЛИЙСКОЙ ФРАЗЕОЛОГИИ
}

\section{Domesticated Birds in Russian, Polish and English Phraseology}

Keywords: phraseology, phraseological units, ornithonym, Russian language, Polish language, English language

Contact: Uniwersytet Śląskiw Katowicach; monika.pawlas96@gmail.com

Фразеологизмы являются важной частью словарного запаса каждого народа, так как в них показаны особенности данного языкового сообщества. Они являются своего рода носителями информации о культуре страны, отражают ее духовный и внутренний мир. Поэтому многие лингвисты занимаются анализом фразеологических единиц, обращая при этом особое внимание на проблему сравнения фразеологии двух и более языков. Таким образом попытка охарактеризовать устойчивые словосочетания с названиями домашних птиц в русском, польском и английском языках кажется актуальной и может способствовать повышению уровня знаний о других культурах через призму национального мировидения.

Каждый язык отличается базой слов, используемой для создания фразеологических единиц. Одними из наиболее часто употребляемых компонентов являются зоонимы, т. е. лексемы, происходящие от наименований животных, которые стали устойчивыми метафорами, обозначающими человеческие черты. Использование компонента-зоонима выполняет функцию оценки человека, описывает его черты характера или внешний вид. То, как он оказывается в составе данных фразеологических единиц, зависит от разных факторов, часто это может быть сходство человека по телосложению (слон), способу поведения (попугай) или характерным внешним особенностям (поросенок). Животным присваиваются разные признаки, в некоторых случаях они соответствуют действительности, например, хищничество (Сzapiga 2008: 4145). Однако в большинстве из них присвоенные признаки являются только результатом субъективного сопоставления определенных черт и ассоциаций, 
которые они вызывают в том или ином языке. Чем их больше, тем чаще они присутствуют в метафорах-зоонимах. Количество фразеологизмов, которые основаны на мотиве животного, очень большое. Особенно птицы довольно часто появляются в устойчивых выражениях во всех анализируемых нами языках (Czapiga 2008: 45-55). Поэтому для описания этой группы животных в лингвистике появился новый научный термин - орнитоним. Эта лексема происходит от греческого ornis (ornitos) 'птица', onima 'имя, название' (Губина, Пронченко 2016: 19), а ее главной целью является выделение, индивидуализация и идентификация одной птицы среди других птиц (Губина, Пронченко 2016: 19).

Важную роль в правильном понимании фразеологии играет концепция языковой картины мира. В межличностном общении для упорядочения и интерпретации действительности необходима языковая система. Благодаря знанию языка мы можем определять мир и конкретным образом воспринимать то, что происходит вокруг нас. Но мы знаем, что ни один язык не может существовать без сообщества, которое его образует. На протяжении веков он был сформирован предыдущими поколениями носителей данного языка на основе их опыта, стереотипов и мировоззрений (Kopińska 2009: 53-76). Вскоре проблема влияния языка на действительность стала вызывать интерес у лингвистов. Они начали проводить исследования, результатом которых было определение концепции языковой картины мира. Одна из попыток выяснить ее была предпринята русскими лингвистами, итак, в научной литературе можно найти такое определение: «Языковая картина мира является своеобразным окном в национальное мировидение и мироощущение. Каждый язык несет в себе особую систему восприятия мира, которая при этом разделяется между всеми носителями этого языка. Особая национальная ментальность находит свое отражение абсолютно во всем: в семантике лексических единиц, в наличии тех или иных грамматических категорий и значений, в оформлении синтаксических и морфологических структур, в особенностях словообразовательных моделей языка и так далее» (Бейсембаев, Жак 2012: 116-120).

Как мы знаем, во фразеологизмах, пословицах, поговорках показаны характерные для сегодняшнего языкового сообщества особенности, а также информация об отношениях между разными народами и взглядах на исторические события (Anusiewicz, Dąbrowska, Fleischer 2000: 24). Таким образом, языковая картина мира связывается с фразеологией. Поэтому в лингвистике появился новый термин: фразеологическая картина мира. Мы его понимаем как «часть языковой картины мира, описанная средствами фразеологии, в которой каждый фразеологический оборот является элементом строгой системы и выполняет 
определенные функции в описании реалий окружающей действительности» (Сираева, Фаткуллина 2014: 42-45). Фразеологическая картина мира кажется быть отражением духа народа и будет отличаться в каждой стране, т. е. некоторые фразеологические единицы, характерные для данной нации, в другой могут быть совершенно неправильно поняты и представлены совсем иначе (Сираева, Фаткуллина 2014: 42-45). Итак, мы можем прийти к такому выводу, что картина действительности, отраженная во фразеологии, несмотря на наличие общих черт с другими языками, является специфической.

Попытка раскрыть характерные черты фразеологии русского, польского и английского народов будет описываться в данной статье. Мы постараемся объяснить различия в значении избранных фразеологизмов с названиями домашних птиц в трех языках, найти их мотивацию и происхождение.

Свой анализ мы хотели бы начать с единиц с компонентом индюк: рус. надулся как индюк, польск. паdymać się (napuszyć się) jak indor, англ. strut (swell) like a turkey-cock. В данном случае имя животного совпадает во всех языках. Когда речь идет об объяснении этого фразеологизма, в русско-английском словаре мы можем найти следующее определение - 'ходить с важным, напыщенным видом' (Кунин 1984: 783). В польском онлайн-словаре также добавляется, что человек, который надувается как индюк, 'неуважительно относится к другим и никого не узнает'. Это выражение мотивировано наблюдением за поведением птицы. В случае опасности индюк надувается и меняет цвет т. наз. кораллов от белого до интенсивно красного (Rak 2001: 134). Таким образом, его внешность может напоминать человека, который считает себя важным, самодовольным.

В дальнейшем обратимся к примерам: рус. как с гуся вода, польск. sptywać jak po kaczce, англ. like water off a duck's back. Анализируя эти устойчивые сравнения, мы можем отметить, что в каждом языке появляется орнитоним, но в русском это гусь, а в польском и английском - утка. Во всех языках значение то же самое. Данные выражения используются, 'когда что-то (особенно критика) не влияет на кого-то, кому-то все равно'2. Фразеологическую единицу можно объяснить, учитывая физиологию птиц, которые имеют копчиковую железу, предохраняющую их перья от намокания. Благодаря смазке этой железы они могут погружаться в воду, оставаясь сухими ${ }^{3}$. Мы можем прийти к выводу, что

\footnotetext{
1 Режим доступа: http://www.edupedia.pl/words/index/show/475373_slownik_frazeologiczny-nadymac_sie _puszyc_sie_jak_indor.html (2020-04-24).

${ }_{2}^{2}$ Режим доступа: https://dictionary.cambridge.org/pl/dictionary/english/like-water-off-a-duck-s-back (2020-0418).

${ }^{3}$ Режим доступа: http://ptaki.info/index_scenariusze.php?dzial=2\&kat=8\&art=58\&limit=48 (2020-04-20).
} 
люди ведут себя как птицы. Подобно птицам, не чувствующим влагу, попадая в воду, они не испытывают эмоций, когда что-то происходит, ничто их не волнует.

Следующий пример: рус. яйца курииу не учат, польск. jajko madrzejsze od kury, англ. don't teach your grandmother to suck eggs. Английский фразеологизм не является точным эквивалентом русского и польского примеров, хотя некоторые источники так сообщают. В английском нет никакого зоонима. В русской и польской единицах появляется тот же самый орнитоним и их значение совпадает. Они относятся к 'молодым людям, которые оспаривают мнение пожилых, опытных людей'4. В свою очередь, в английском языке выражение имеет общий характер и обозначает 'дать совет кому-то о деле, о котором он уже знает больше, чем вы'5. В русском фразеологизме курица сравнивается со взрослым человеком, у которого большой опыт, а яйцо с незрелым, который еще не так много испытал в своей жизни, но несмотря на это, он не хочет слушать советов пожилых. Польское выражение jajko madrzejsze od kury происходит из стихотворения Яна Бжехвы под названием «Яйцо», в котором яйцо не прислушивается к советам курицы, предупреждающей о различных опасностях, и остается сваренным в кастрюле 6 . Стоит еще добавить, что в английских источниках отмечается, что впервые в литературе фразеологизм don't teach your grandmother to suck eggs появился в 1707 году в переводе одного из поэтов барокко Франсиско де Кеведо, выполненным Джоном Стивенсом 7 Мотивация этого выражения заключается в чрезвычайной простоте действия, так как сосание яиц - это обычный способ съесть их, сделав маленькую дырочку на каждом конце и засосав содержимое в рот. Итак, если кто-то старается кого-то научить этому несложному методу еды это желание оскорблять его, объясняя вещи, которые он знает так же, как и я, или лучше.

Очередной пример - это: рус. гусь свинье не товарищ, польск. baran wilkowi nie towarzysz, англ. oil and water don't mix. Здесь только в русском языке появляется один орнитоним и зооним, в польском два зоонима, а в английском языке нет никаких названий животных. Единицы надо понимать во всех языках таким образом, 'если люди с самого начала различаются по интересам и характерам, они не добьются успехов в сотрудничестве или дружбе'8.

\footnotetext{
${ }^{4}$ Режим доступа: http://www.fraze.ru/index.php/poslovitsy-pogovorki/poslov-na-bukvu-ya/yajtsa-kuritsu-neuchat (2020-04-14).

5 Режим доступа: https://dictionary.cambridge.org/pl/dictionary/english/teach-your-grandmother-to-suck-eggs (2020-04-14).

${ }^{6}$ Режим доступа: http://wiersze.juniora.pl/brzechwa/brzechwa_j01.html (2020-04-14).

${ }^{7}$ Режим доступа: https://www.phrases.org.uk/meanings/118200.html (2020-04-18).

${ }^{8}$ Режим доступа: http://www.fraze.ru/index.php/poslovitsy-pogovorki/poslov-na-bukvu-g/gus-svine-ne-tovarish (2020-04-18).
} 
Появление данных зоонимов в русском языке, вероятно, связано с фактом, что эти животные принадлежат к разным классам, т. е. к птицам и млекопитающим, зато в польском языке сопоставляются волк и баран, которые принадлежат к одному классу, причем первый является хищником, а второй нет и более того может стать одной из его жертв. Здесь надо также отметить, что слово товарищ когда-то имело более широкое значение, потому что оно использовалось как приветливое название брата (Мокиенко 2017: 112). Английский эквивалент связан с различиями в плотности обеих жидкостей, так как плотность масла меньше плотности воды, поэтому масло плавает на ее поверхности ${ }^{9}$. Оттуда и пришло это выражение, которое можно сравнить с людьми, не умеющими найти общего языка.

Бывает так, что орнитоним утка встречается в составе только английской единицы. К примеру: рус. в такую погоду и собаку на улииу не выгонишь, польск. pogoda pod psem, англ. fine (lovely) day (week, weather) for the (young) ducks. В польском и русском языках появляется зооним собака. Поговорка функционирует в разговорном языке и 'используется для определения мокрой и дождливой погоды' (Кунин 1984: 228). Происхождение выражения в английском языке связано с природой уток, поскольку они являются водными животными, кроме этого, утки любят селиться в лужах, созданных дождем. Возможно, русский вариант относится к тому факту, что собака - это домашнее животное, и во многих случаях часто даже рассматривается как член семьи. В свою очередь, поговорку в польском языке трудно четко объяснить. Словосочетание pod psem относится к собаке не только в связи с погодой, но и в связи с чьим-то характером или едой ${ }^{10}$. Более того, согласно словарю польского языка, фразеологизмы с компонентом собака, имеющие отрицательный оттенок, популярны в Польше и очень часто встречаются в разговорной речи ${ }^{11}$.

В указанном ниже примере снова только в английском фразеологизме появляется орнитоним: рус. быть не первой молодости, польск. nie jest pierwszej młodości, англ. be no chicken или no spring chicken. 'Выражение употребляется в разговорной речи и имеет негативный оттенок, а относится к человеку, который уже не молод ${ }^{12}$. Мотивация английского эквивалента связана с тем, что фермеры обнаружили, что цыплята, родившиеся весной, стоили дороже, чем «старые», пережившие зиму. Итак, они пытались продать старых птиц как

\footnotetext{
${ }^{9}$ Режим доступа: http://www.scienceprojectideas.co.uk/why-oil-water-dont-mix.html (2020-04-18).

${ }^{10}$ Режим доступа: https://sjp.pwn.pl/poradnia/haslo/pierwsze-koty-i-pogoda-pod-psem;1809.html (2020-04-20).

${ }^{11}$ Режим доступа: https://sjp.pwn.pl/poradnia/haslo/pierwsze-koty-i-pogoda-pod-psem;1809.html (2020-04-21).

12 Режим доступа: https://wsjp.pl/index.php?id_hasla=15456\&id_znaczenia=4765970\&l=6\&ind=0 (2020-04$18)$.
} 
«новорожденных». Тогда покупатели жаловались, что они не первой молодости (no spring chicken $)^{13}$.

В нашей статье мы проанализировали избранные фразеологизмы с птичьим компонентом в трех языках: русском, польском и английском. В них появились такие домашние птицы, как: индейка, гусь, утка, курица и цыпленок. Результаты наших исследований показали, что они широко распространены в культуре данных наций. Стоит подчеркнуть, что в большинстве приведенных фразеологизмов появляются разные названия птиц, но иногда встречаются эквиваленты один к одному. Примером здесь могут служить выражения со словом индюк, в которых имя животного совпадает во всех языках. Кроме того, можно заметить, что во многих устойчивых словосочетаниях только в английском языке появляются орнитонимы. Стоит еще обратить внимание на мотивацию рассмотренных фразеологизмов, так как она связана с наблюдением за поведением и внешностью птиц, но иногда причиной может быть нелингвистический фактор, напр., расположение страны. Резюмируя, можно заметить, что фразеологизмы с компонентом-орнитонимом играют важную роль во фразеологии каждого из анализируемых языков, а национально-культурный фактор может повлиять на продуктивность отдельных орнитонимов.

\section{Summary}

The principle aim of the article is to shed light on the differences between Russian, Polish and English idioms containing words from the domesticated bird class. The article consists of three main parts. The first one presents a description of the terms: zoononym and ornithonym. The next section explains the linguistic worldview and its relation to phraseology. In the last part of the article the idioms with words from the domesticated bird class are analysed. Particular examples of the idioms are compared with their equivalents in another languages in accordance with their meaning and origin.

\section{Литература}

Бейсембаев, А. Р., Жак, С. В. Языковая картина мира как производная национального менталитета. Вестник Инновационного Евразийского университета. 2012 (2), с. 116-120.

\footnotetext{
${ }^{13}$ Режим доступа: https://www.gingersoftware.com/content/phrases/no-spring-chicken/ (2019-04-18). 
Губина, Д. И., Пронченко, Е. Н. Орнитоним как объект лингвистического исследования. Вестник ПГУ. 2016 (4), с. 19-25.

Кунин, А. В. Англо-русский фразеологический словарь. Москва: Русский язык, 1984.

Мокиенко, В. В. Давайте правильно говорить по-русски! Пословиць: как их правильно понимать и употреблять, толкование, происхождение, иноязычные соответствия. Москва: Центрполиграф, 2017.

Сираева, Р. Т., Фаткуллина, Ф. Г. Фразеологическая картина мира: основное содержание и признаки. Современные проблемы науки и образования. 2014 (3), с. 42-45.

Anusiewicz, J., Dąbrowska, A., Fleischer, M. Językowy obraz świata i kultura: projekt koncepcji badawczej. In: Dąbrowska, A., Anusiewicz, J., Fleischer, M. (eds.) Język a Kultura. T. 13. Wrocław: Wydawnictwo Uniwersytetu Wrocławskiego, 2000, s. 11-44.

Czapiga, A. Antroponimiczne metafory odzwierzęce $w$ języku polskim, rosyjskim i angielskim. Rzeszów: Wydawnictwo Uniwersytetu Rzeszowskiego, 2008.

Kopińska, M. Język jako narzędzie interpretacji rzeczywistości - językowy obraz świata. Mundu bat begirada anitz. Un mundo michas miradas. 2009 (2), s. 53 76.

Rak, M. Językowo-kulturowy obraz zwierząt utrwalony $w$ animalistycznej frazeologii gwar Gór Świętokrzyskich i Podtatrza. Kraków: Scriptum, 2001.

\section{Интернет-источники}

Режим доступа: http://www.fraze.ru/index.php/poslovitsy-pogovorki/poslov-nabukvu-g/gus-svine-ne-tovarish (2020-04-18).

Режим доступа: http://ptaki.info/index_scenariusze.php?dzial=2\&kat=8\&art=58\& limit=48 (2020-04-20).

Режим доступа: http://www.edupedia.pl/words/index/show/475373_slownik_ frazeologiczny-nadymac_sie_puszyc_sie_jak_indor.html (2020-03-31).

Режим доступа: http://www.fraze.ru/index.php/poslovitsy-pogovorki/poslov-nabukvu-ya/yajtsa-kuritsu-ne-uchat (2020-04-14).

Режим доступа: http://www.scienceprojectideas.co.uk/why-oil-water-dont-mix.html (2020-04-18). 
Режим доступа: https://dictionary.cambridge.org/pl/dictionary/english/like-water-offa-duck-s-back (2020-04-18).

Режим доступа: https://dictionary.cambridge.org/pl/dictionary/english/teach-yourgrandmother-to-suck-eggs (2020-04-14).

Режим доступа: https://dictionary.cambridge.org/p1/dictionary/english/be-up-with-thelark (2020-04-03).

Режим доступа: https://dinoanimals.pl/blogi/silencenature/skowronek-zwyczajnyptak-zwiastujacy-wiosne/ (2020-04-03).

Режим доступа: https://sjp.pwn.pl/poradnia/haslo/pierwsze-koty-i-pogoda-podpsem;1809.html (2020-04-20).

Режим доступа: https://sjp.pwn.pl/poradnia/haslo/pierwsze-koty-i-pogoda-podpsem;1809.html (2020-04-18).

Режим доступа: https://wsjp.pl/index.php?id_hasla=15456\&id_znaczenia=4765970\&l $=6 \&$ ind $=0(2020-04-05)$.

Режим доступа: https://www.gingersoftware.com/content/phrases/no-spring-chicken/ 2020-04-18).

Режим доступа: https://www.phrases.org.uk/meanings/118200.html (2020-04-18).

Режим доступа: http://wiersze.juniora.pl/brzechwa/brzechwa_j01.html (2020-04-14). 